\title{
Analisis Kebutuhan Mahasiswa terhadap E-modul Fisika Matematika
}

\author{
Nadia Natalia Simamora ${ }^{1, *}$, Astalini $^{1),}$, Darmaji $^{1)}$ \\ ${ }^{1)}$ Pendidikan Fisika Fakultas Keguruan dan Ilmu Pendidikan, Universitas Jambi \\ *nadianataliaa12@gmail.com
}

Abstrak: Penelitian ini bertujuan untuk menganalisis kebutuhan mahasiswa terhadap e-modul Fisika Matematika. Penelitian ini menggunakan jenis penelitian survei dengan pendekatan penelitian kuantitatif dan kualitatif. Populasi penelitian adalah mahasiswa Pendidikan Fisika Universitas Jambi dengan jumlah sampel 35 mahasiswa. Pengambilan sampel dilakukan dengan menggunakan teknik purposive sampling. Teknik analisis data yang digunakan dalam penelitian adalah analisis data statistik deskriptif dan analisis miles dan huberman. Hasil penelitian menunjukkan bahwa 42,86\% mahasiswa setuju adanya e-modul Fisika Matematika dengan nilai mean 21,94 berada pada kriteria setuju. Ini didukung dengan hasil data kualitatif melalui wawancara yang menyatakan bahwa mahasiswa membutuhkan adanya sumber belajar tambahan e-modul Fisika Matematika agar mahasiswa dapat memahami materi pembelajaran. Penggunaan e-modul pada mata kuliah Fisika Matematika dapat membantu mahasiswa belajar secara mandiri. Penelitian ini dapat dijadikan sebagai referensi untuk penelitian e-modul Fisika Matematika ke depannya.

Kata Kunci: Fisika Matematika 1, E-Modul, Kebutuhan Mahasiswa

\section{PENDAHULUAN}

Kemajuan teknologi membuat dunia seakan tidak ada batasnya (Sopacua et al., 2020). Hal ini memberi pengaruh terhadap perkembangan pendidikan di dunia (Kimianti \& Prasetyo, 2019). Pendidikan merupakan kegiatan yang sangat penting bagi semua individu (Simamora et al., 2020). Karena pada dasarnya pendidikan menjadi wadah untuk membantu peserta didik dalam mengembangkan potensinya. Sehingga dibutuhkan inovasi dan penggunaan teknologi yang optimal sebagai media pembelajaran yang menarik agar dapat diterima oleh siswa (Purnami \& Winoto, 2020; Ilmi et al., 2021).

Media pembelajaran adalah alat bantu dalam proses belajar mengajar. Media pembelajaran dibedakan menjadi media cetak (tradisional) dan media elektronik (Suparmi et al., 2020). Penggunaan media pembelajaran elektronik dapat membantu proses pembelajaran menjadi lebih efektif dan efisien guna meningkatkan kemampuan siswa (Asrowi et al., 2019). Salah satu media pembelajaran berbasis elektronik untuk membantu kegiatan belajar mengajar ialah e-modul. E-modul merupakan inovasi terbaru dari modul konvensional. Kegiatan belajar yang menggunakan e-modul sebagai media pembelajaran adalah Fisika Matematika.

Fisika Matematika merupakan gabungan antara mata pelajaran fisika dan matematika (Astalini et al., 2021). Fisika matematika juga merupakan mata kuliah wajib dalam Program Studi Pendidikan Fisika FKIP Universitas Jambi. Buku utama yang digunakan dalam mata kuliah Fisika Matematika I ialah Mathematical Methods in the Physical Sciences karya Mary L. Boas dengan bahasa pengantar bahasa Inggris (Astalini et al., 2021). Bahasa asing yang diterjemahkan ke dalam bahasa indonesia masih sulit dimegerti oleh mahasiswa (Astalini et al., 2021). Sehingga mahasiswa mengalami kesulitan dalam memahami isi buku utama dengan baik. Selain itu, kesulitan mahasiswa dalam mempelajari fisika matematika salah satunya disebabkan oleh kurangnya kemampuan pemecahan masalah matematik mahasiswa (Saputri, Fadilah \& Wahyudi, 2016). Mengacu pada permasalahan tersebut maka diperlukan upaya untuk pemecahan masalah yang terjadi pada mahasiswa. Salah satu solusi dalam penguasaan materi oleh mahasiswa dapat menggunakan e-modul, e-modul dapat membantu mahasiswa dalam mempelajari materi pelajaran secara mandiri sebagai sumber belajar baru yang memberikan pengalaman belajar (Asrial et al., 2020). 
Penelitian yang relevan dengan penelitian ini adalah penelitian yang dilakukan oleh Ellianawati \& Wahyuni (2012) tentang pengembangan bahan ajar Fisika Matematika berbasis self regulated learning sebagai upaya peningkatan kemampuan belajar mandiri. Lalu penelitian yang dilakukan oleh Amilia, Andriani \& Zulherman (2016) dengan judul "Pengembangan Bahan Ajar Cetak Mata Kuliah Fisika Matematika Pokok Bahasan Bilangan Kompleks Di Program Studi Pendidikan Fisika Universitas Sriwijaya” dengan hasil penelitian menunjukkan bahwa bahan ajar yang dikembangkan sudah tergolong valid dan praktis, sehingga layak digunakan sebagai bahan ajar tambahan pada mata kuliah Fisika Matematika. Serta penelitian oleh Saputri, Fadilah \& Wahyudi (2016) tentang Efektivitas Penggunaan Buku Ajar Fisika Matematika Berbasis Inkuiri dalam Perkuliahan Fisika Matematika menunjukkan bahwa peningkatan kemampuan pemecahan masalah matematis mahasiswa pada perkuliahan Fisika Matematika tergolong baik, dan respon mahasiswa terhadap buku ajar tergolong baik maka penggunaan buku ajar Fisika Matematika berbasis inquiry efektif dalam perkuliahan Fisika Matematika.

Berdasarkan uraian tersebut maka penting dilakukan penelitian mengenai analisis kebutuhan mahasiswa terhadap e-modul Fisika Matematika dengan tujuan untuk mengetahui kebutuhan mahasiswa terhadap emodul Fisika Matematika.

\section{METODE}

Penelitian ini menggunakan jenis penelitian survei. Adapun pendekatan penelitian yang digunakan ialah pendekatan penelitian kuantitatif dan kualitatif. Penelitian kuantitatif digunakan untuk melakukan penelitian terhadap suatu populasi atau sampel tertentu, instrumen pengumpulan data, penelitian dan analisis atau statistik data (Darmaji, Kurniawan, Astalini, Kurniawan, et al., 2019). Penelitian kualitatif merupakan studi tentang sifat fenomena (Busetto, Wick \& Gumbinger, 2020).

Populasi dalam penelitian ini merupakan mahasiswa pendidikan fisika angkatan tahun 2019 universitas Jambi. Sampel yang digunakan dalam penelitian berjumlah 35 mahasiswa. Pengambilan sampel perlu ditentukan metode penelitiannya (Simpson \& Lord, 2015). Jumlah sampel adalah jumlah populasi sehingga dibutuhkan strategi pengambilan sampel yang tepat (Sumual \& Ali, 2017). Adapun sampel yang digunakan pada penelitian ini diperoleh dengan menggunakan teknik purposive sampling. Purposive sampling yang diterapkan digunakan untuk memperoleh subjek penelitian berdasarkan pertimbangan khusus yaitu kebutuhan penelitian (Ahmad et al., 2020). Pengambilan sampel ditetapkan dengan kriteria bahwa mahasiswa telah mengontrak mata kuliah Fisika Matematika I di semester 3 dan mahasiswa memiliki kemampuan dasar dalam mengoperasikan laptop atau handphone untuk belajar.

Data dalam penelitian ini diperoleh dari data kuantitatif dengan menggunakan angket kebutuhan mahasiswa dan data kualitatif yang diperoleh dari wawancara. Angket yang digunakan dalam penelitian merupakan angket kebutuhan mahasiswa terhadap bahan ajar Fisika Matematika dengan 6 pernyataan guna untuk melakukan analisis terhadap bahan ajar yang digunakan dan yang akan di kembangkan. Pengumpulan data dilakukan dengan cara menyebarkan angket atau kuesioner melalui Google Form kepada mahasiswa kemudian mengisi pernyataan yang telah diberikan. Angket merupakan metode untuk mengumpulkan dan mengukur segala informasi dengan mudah dari sampel penelitian menggunakan skala penilaian (Elmendorf \& Song, 2015; Lupi et al., 2017). Sedangkan wawancara dilakukan pada mahasiswa diberikan 12 pertanyaan.

Angket yang digunakan dalam penelitian ini dibuat dengan menggunakan skala likert. Anget penelitian yang diberikan kepada mahasiswa memiliki skor yang berbeda-beda, yaitu Sangat Setuju $=5$, Setuju $=4$, Cukup Setuju $=3$, Tidak Setuju $=2$, dan Sanggat Tidak Setuju $=1$. Adapun kriteria dari angket kebutuhan mahasiswa yang diberikan, yaitu:

Tabel 1. Kriteria Kebutuhan Mahasiswa

\begin{tabular}{cc}
\hline Interval & Kriteria \\
\hline $6,0-10,8$ & Sangat Tidak Setuju \\
$10,9-15,6$ & Tidak Setuju \\
$15,7-20,4$ & Cukup Setuju \\
$20,5-25,2$ & Setuju \\
$25,3-30,0$ & Sangat Setuju \\
\hline
\end{tabular}


Teknik analisis data dalam penelitian ini untuk data kuantitatif menggunakan analisis statistika deskriptif. Data kuantitatif yang dianalisis menggunakan statistik deskriptif seperti perhitungan mean, median, modus, dan lain-lain (Odhier, Odhier, Ajowi \& Mwebi, 2019). Data kualitatif yang diperoleh dianalisis dengan analisis miles \& huberman. Kegiatan dalam analisis data miles \& huberman dilakukan dengan reduksi data, penyajian data, dan penarikan kesimpulan (Sugiyono, 2020)

\section{HASIL DAN PEMBAHASAN}

Penelitian ini dilakukan untuk menganalisis kebutuhan mahasiswa terhadap e-modul Fisika Matematika. Hasil data didapatkan dari penyebaran angket kebutuhan mahasiswa dan wawancara pada mahasiswa Pendidikan Fisika Universitas Jambi sebanyak 35 mahasiswa. Data kuantitatif diperoleh menggunakan angket kebutuhan mahasiswa dengan hasil analisis data statistik deskriptif menggunakan SPSS 22, dapat dilihat pada tabel 2 di bawah ini:

Tabel 2. Hasil Statistik Deskriptif Analisis Kebutuhan Mahasiswa

\begin{tabular}{ccccccc}
\hline \multicolumn{2}{c}{ Klasifikasi } & Total & $\%$ & Mean & Min & Max \\
\cline { 1 - 3 } Interval & Kriteria & & & & \\
\hline $6,0-10,8$ & Sangat Tidak Setuju & 0 & 0 & & & \\
$10,9-15,6$ & Tidak Setuju & 0 & 0 & & & 30 \\
$15,7-20,4$ & Cukup Setuju & 13 & 37,14 & 21,94 & 15 & \\
$20,5-25,2$ & Setuju & 15 & 42,86 & & & \\
$25,3-30,0$ & Sangat Setuju & 7 & 20 & & & \\
\hline
\end{tabular}

Dari tabel 2 statistik deskriptif kebutuhan mahasiswa terhadap e-modul Fisika Matematika menunjukkan bahwa mahasiswa dengan kriteria cukup setuju sebanyak 37,14\% (13 dan 35 mahasiswa), mahasiswa dengan kriteria setuju sebanyak 42,86\% (15 dari 35 mahasiswa), dan mahasiswa dengan kriteria sangat setuju sebanyak 20\% (7 dari 35 mahasiswa). Dapat dilihat bahwa mahasiswa dengan kriteria tidak setuju dan sangat tidak setuju sebanyak $0 \%$. Adapun nilai mean yang diperoleh sebesar 21,94 yang berada pada kriteria setuju dengan nilai minimum 15 dan nilai maksimum 30. Hasil ini menunjukkan bahwa mahasiswa membutuhkan adanya e-modul Fisika Matematika.

Data kualitatif diperoleh menggunakan wawancara dengan mewawancarai 5 mahasiswa. Adapun hasil wawancara dapat dilihat pada tabel 3 berikut ini:

Tabel 3. Hasil Wawancara

\begin{tabular}{|c|c|c|c|c|c|c|}
\hline \multirow[b]{2}{*}{ No } & \multirow[b]{2}{*}{ Pertanyaan } & \multicolumn{5}{|c|}{ Jawaban } \\
\hline & & $\begin{array}{c}\text { Mahasiswa } \\
1\end{array}$ & $\begin{array}{c}\text { Mahasiswa } \\
2\end{array}$ & $\begin{array}{c}\text { Mahasiswa } \\
3\end{array}$ & $\begin{array}{c}\text { Mahasiswa } \\
4\end{array}$ & $\begin{array}{c}\text { Mahasiswa } \\
5\end{array}$ \\
\hline 1 & $\begin{array}{c}\text { Apakah saudara/i } \\
\text { sudah mengikuti } \\
\text { perkuliahan Fisika } \\
\text { Matematika? }\end{array}$ & Sudah & Sudah & Pernah & Sudah & Sudah \\
\hline 2 & $\begin{array}{l}\text { Apakah ini pertama } \\
\text { kali saudara/i } \\
\text { mengikuti } \\
\text { perkuliahan Fisika } \\
\text { Matematika? }\end{array}$ & Iya & Tidak & Iya & $\begin{array}{c}\text { Iya, semester } \\
3\end{array}$ & Iya \\
\hline 3 & $\begin{array}{c}\text { Berapa kali } \\
\text { saudara/i mengikuti } \\
\text { perkuliahan Fisika } \\
\text { Matematika? }\end{array}$ & 1 semester & $\begin{array}{c}\text { Satu kali } \\
\text { yaitu pada } \\
\text { semester } 3\end{array}$ & Satu semester & $\begin{array}{c}\text { Alhamdulillah } \\
\text { cuma satu kali } \\
\text { selama } \\
\text { semester } 3 \\
\end{array}$ & $\begin{array}{c}\text { Satu kali yaitu } \\
\text { pada semester } \\
3\end{array}$ \\
\hline 4 & $\begin{array}{c}\text { Apakah saudara/i } \\
\text { memiliki literatur } \\
\text { perkuliahan Fisika } \\
\text { Matematika? }\end{array}$ & Ada & Punya & $\begin{array}{l}\text { Catatan materi } \\
\text { yang dijelaskan } \\
\text { dosen }\end{array}$ & Ya & Iya \\
\hline
\end{tabular}




\begin{tabular}{|c|c|c|c|c|c|c|}
\hline 5 & $\begin{array}{c}\text { Bagaimana menurut } \\
\text { saudara/i tentang } \\
\text { literatur yang } \\
\text { digunakan pada } \\
\text { perkuliahan Fisika } \\
\text { Matematika? }\end{array}$ & $\begin{array}{l}\text { Cukup } \\
\text { membantu } \\
\text { saya dalam } \\
\text { belajar. }\end{array}$ & $\begin{array}{c}\text { Sulit } \\
\text { dipahami } \\
\text { karena } \\
\text { menggunakan } \\
\text { bahasa } \\
\text { Inggris dan } \\
\text { penurunan } \\
\text { rumus tidak } \\
\text { terlalu } \\
\text { mendetail. }\end{array}$ & $\begin{array}{l}\text { Sulit dipahami } \\
\text { dan } \\
\text { membosankan. }\end{array}$ & $\begin{array}{l}\text { Sudah bagus } \\
\text { dan sesuai. } \\
\text { Teman-teman } \\
\text { saya di } \\
\text { universitas } \\
\text { lain jg } \\
\text { menggunakan } \\
\text { sumber yang } \\
\text { sama seperti } \\
\text { saya jadi tidak } \\
\text { terkendala } \\
\text { atau } \\
\text { tertinggal. }\end{array}$ & Biasa. \\
\hline 6 & $\begin{array}{l}\text { Apakah saudara/i } \\
\text { memiliki kendala } \\
\text { atau masalah selama } \\
\text { perkuliahan Fisika } \\
\text { Matematika? }\end{array}$ & $\begin{array}{c}\text { Ada, saya } \\
\text { kurang } \\
\text { mengerti } \\
\text { jika materi } \\
\text { dijelaskan } \\
\text { secara } \\
\text { singkat } \\
\text { saja, saya } \\
\text { setuju jika } \\
\text { materinya } \\
\text { dijelaskan } \\
\text { secara } \\
\text { detail } \\
\text { sehingga } \\
\text { dapat } \\
\text { mudah } \\
\text { dipahami. }\end{array}$ & $\begin{array}{l}\text { Kendala yang } \\
\text { dimiliki } \\
\text { hanya kurang } \\
\text { memahami. }\end{array}$ & Punya & Ada & $\begin{array}{c}\text { Iya, saya } \\
\text { membutuhkan } \\
\text { waktu lebih } \\
\text { lama untuk } \\
\text { memahami } \\
\text { materi dan } \\
\text { saya harus } \\
\text { mengulang } \\
\text { ulang materi } \\
\text { agar dapat } \\
\text { memahaminya }\end{array}$ \\
\hline 7 & $\begin{array}{c}\text { Apakah salah satu } \\
\text { kendala atau } \\
\text { masalah perkuliahan } \\
\text { terletak pada bahan } \\
\text { ajar? }\end{array}$ & Iya & Iya & $\begin{array}{c}\text { Iya, karena } \\
\text { bahan ajar } \\
\text { yang } \\
\text { digunakan } \\
\text { berbahasa } \\
\text { inggris } \\
\text { sehingga saya } \\
\text { sedikit } \\
\text { kesulitan } \\
\text { memahaminya }\end{array}$ & $\begin{array}{c}\text { Iya ini salah } \\
\text { satunya }\end{array}$ & Tidak \\
\hline 8 & $\begin{array}{l}\text { Apakah saudara/i } \\
\text { senang jika Fisika } \\
\text { Matematika ada } \\
\text { dalam bentuk e- } \\
\text { modul? }\end{array}$ & Senang & $\begin{array}{c}\text { Senang } \\
\text { selama } \\
\text { mudah } \\
\text { dipahami }\end{array}$ & Senang & Senang sekali & Senang \\
\hline 9 & $\begin{array}{l}\text { Bagaimana menurut } \\
\text { saudara/i jika Fisika } \\
\text { Matematika } \\
\text { dibuatkan e-modul } \\
\text { perkuliahan? }\end{array}$ & $\begin{array}{c}\text { Menurut } \\
\text { saya, } \\
\text { mahasiswa } \\
\text { dapat lebih } \\
\text { mudah } \\
\text { mengakses } \\
\text { nya, dan } \\
\text { dapat } \\
\end{array}$ & $\begin{array}{l}\text { Saya setuju } \\
\text { dengan } \\
\text { dibuatkan e- } \\
\text { modul } \\
\text { tersebut. }\end{array}$ & $\begin{array}{c}\text { Senang, } \\
\text { karena sangat } \\
\text { membantu. }\end{array}$ & $\begin{array}{c}\text { Akan sangat } \\
\text { membantu } \\
\text { mahasiswa } \\
\text { untuk lebih } \\
\text { memahami } \\
\text { materi dan } \\
\text { tidak bosan } \\
\text { membacanya. }\end{array}$ & $\begin{array}{c}\text { Bagus, karena } \\
\text { kita Zaman } \\
\text { sekarang Hp } \\
\text { itu merupakan } \\
\text { sesuatu yang } \\
\text { tidak pernah } \\
\text { lepas dari } \\
\text { genggaman } \\
\end{array}$ \\
\hline
\end{tabular}




\begin{tabular}{|c|c|c|c|c|c|c|}
\hline & & $\begin{array}{c}\text { belajar } \\
\text { dimanapun } \\
\text { dan } \\
\text { kapanpun. }\end{array}$ & & & & $\begin{array}{c}\text { kan jadi untuk } \\
\text { adanya e- } \\
\text { modul ini } \\
\text { mempermudah } \\
\text { mahasiswa } \\
\text { mengakses nya } \\
\text { tanpa harus } \\
\text { terbebani } \\
\text { dalam bentuk } \\
\text { cetakan. } \\
\end{array}$ \\
\hline 10 & $\begin{array}{c}\text { Jika ada e-modul } \\
\text { Fisika Matematika, } \\
\text { apakah menurut } \\
\text { saudara/i dapat } \\
\text { membantu proses } \\
\text { perkuliahan Fisika } \\
\text { Matematika? }\end{array}$ & $\begin{array}{c}\text { Sangat } \\
\text { membantu }\end{array}$ & Tentu saja iya & Tentu & $\begin{array}{c}\text { Tentu sangat } \\
\text { membantu }\end{array}$ & $\begin{array}{l}\text { Iya, tentu } \\
\text { sangat } \\
\text { membantu }\end{array}$ \\
\hline 11 & $\begin{array}{c}\text { Jika ada e-modul } \\
\text { Fisika Matematika } \\
\text { menggunakan } \\
\text { bahasa Indonesia, } \\
\text { apakah menurut } \\
\text { saudara/i e-modul } \\
\text { tersebut dapat } \\
\text { membantu proses } \\
\text { perkuliahan Fisika } \\
\text { Matematika? }\end{array}$ & $\begin{array}{c}\text { Sangat } \\
\text { membantu. }\end{array}$ & $\begin{array}{c}\text { Iya } \\
\text { membantu. }\end{array}$ & Iya. & Tentu. & $\begin{array}{c}\text { Sangat } \\
\text { membantu } \\
\text { bagi saya, } \\
\text { karena selama } \\
\text { ini } \\
\text { menggunakan } \\
\text { yang berbahasa } \\
\text { inggris } \\
\text { sehingga saya } \\
\text { harus bisa } \\
\text { memahaminya. } \\
\text { Jadi, dengan } \\
\text { menggunakan } \\
\text { bahasa } \\
\text { indonesia } \\
\text { dapat } \\
\text { membantu } \\
\text { saya } \\
\text { memahami } \\
\text { materi. }\end{array}$ \\
\hline
\end{tabular}

Hasil wawancara dari 5 mahasiswa pada pertanyaan 1 menunjukkan jawaban bahwa mahasiswa sudah pernah mengikuti perkuliahan Fisika Matematika. Pada pertanyaan 2 dan pertanyaan 3 mahasiswa menunjukkan jawaban bahwa mahasiswa mengikuti perkuliahan Fisika Matematika di semester 3. Lalu jawaban mahasiswa pada pertanyaan 4 menunjukkan bahwa mahasiswa memiliki literatur untuk perkuliahan Fisika Matematika yaitu buku cetak yang menggunakan bahasa inggris dan catatan materi yang dijelaskan dosen. Selanjutnya jawaban dari pertanyaan 5 secara keseluruhan menunjukkan bahwa literatur yang digunakan selama perkuliahan Fisika Matematika sudah bagus karena mahasiswa dari universitas lain juga menggunakan buku yang sama dan cukup membantu dalam belajar namun sulit dipahami karena menggunakan bahasa inggris. Pada pertanyaan 6 dan pertanyaan 7 mahasiswa menjawab bahwa memiliki kendala selama perkuliahan Fisika Matematika, salah satunya ialah bahan ajar. Jawaban mahasiswa dari pertanyaan 8 menunjukkan bahwa mahasiswa senang jika selama perkuliahan Fisika Matematika ada bahan ajar berbentuk e-modul. Lalu jawaban mahasiswa dari pertanyaan 9 menyatakan bahwa dengan menggunakan e-modul dalam belajar Fisika Matematika dapat membantu mahasiswa dalam memahami materi, tidak membosankan, mudah diakses tanpa terbebani untuk membawa bahan ajar berbentuk cetak. Pada pertanyaan 10 secara keseluruhan mahasiswa menjawab bahwa dengan adanya e-modul dapat membantu proses perkuliahan Fisika Matematika. Pertanyaan 11 mahasiswa menjawab bahwa adanya e-modul Fisika Matematika 
menggunakan bahasa indonesia dapat membantu proses perkuliahan Fisika Matematika dan dapat membantu dalam memahami materi Fisika Matematika.

Berdasarkan hasil wawancara yang diperoleh menunjukkan bahwa mahasiswa sangat membutuhkan adanya sumber belajar tambahan e-modul Fisika Matematika. E-modul Fisika Matematika dapat membantu mahasiswa dalam memahami materi pembelajaran. Penggunaan e-modul Fisika Matematika yang dapat diakses menggunakan smartphone membuat mahasiswa dapat belajar dimanapun dan kapanpun tanpa harus membawa buku cetak. Penggunaan bahasa pada e-modul Fisika Matematika ini juga memudahkan mahasiswa dalam memahami materi Fisika Matematika karena bahasa yang digunakan ialah bahasa Indonesia. Hasil wawancara ini pun didukung dengan hasil data statistik deskriptif dari angket kebutuhan mahasiswa yang menunjukkan bahwa 20\% mahasiswa sangat setuju dan 42,86\% mahasiswa setuju serta 37,14\% mahasiswa cukup setuju adanya e-modul Fisika Matematika dan 0\% mahasiswa dengan kriteria tidak setuju maupun sangat tidak setuju. Data statistik juga menunjukkan mean sebesar 21,94 yang berada pada kriteria setuju.

Data hasil statistik deskriptif dan wawancara terhadap e-modul Fisika Matematika menunjukkan bahwa mahasiswa setuju dengan adanya e-modul Fisika Matematika yang menggunakan bahasa Indonesia sehingga mudah dipahami dan memiliki penurunan rumus yang detail. Dengan adanya e-modul Fisika Matematika mahasiswa dapat belajar secara mandiri sebelum adanya kegiatan belajar di kelas dan dapat mengulang kembali pembelajaran yang telah dilakukan di kelas. Serta dengan mengerjakan soal-soal yang ada pada e-modul dapat meningkatkan kemampuan pemahaman mahasiswa terhadap materi Fisika Matematika. Selain itu, penggunaan e-modul dapat meningkatkan minat belajar mahasiswa dan perhatian mahasiswa karena e-modul menggunakan bahasa yang mudah dipahami dan desain yang menarik serta tidak membosankan.

\section{SIMPULAN}

Berdasarkan hasil penelitian yang telah dilakukan diperoleh bahwa mahasiswa membutuhkan e-modul Fisika Matematika sebagai media pembelajaran tambahan. Hasil data statistik deskriptif menunjukkan bahwa 42,86\% mahasiswa setuju adanya e-modul Fisika Matematika. Data statistik didukung dengan data kualitatif dari hasil wawancara yang menyatakan bahwa dengan adanya e-modul dapat membantu mahasiswa belajar secara mandiri dimanapun dan kapanpun. Sehingga penggunaan e-modul Fisika Matematika dapat membantu mahasiswa dalam memahami materi pembelajaran dan dapat meningkatkan pemahaman mahasiswa serta dapat meningkatkan minat belajar mahasiswa.

\section{Ucapan Terima Kasih}

Peneliti mengucapkan terimakasih kepada program studi Pendidikan Fisika Universitas Jambi yang telah mendukung dan memberikan fasilitas kepada peneliti untuk menyelesaikan penelitian, dan kepada mahasiswa/i Pendidikan Fisika angkatan 2019 Universitas Jambi yang telah memberikan kesempatan kepada peneliti untuk melakukan penelitian sehingga terlaksana dengan baik serta pihak-pihak lain yang telah berkontribusi dalam penelitian ini.

\section{Daftar Pustaka}

Ahmad, J., Rahmawati, D., \& Anwar, R. B. (2020). Proses Translasi Representasi Siswa Dalam Menyelesaikan Permasalahan Matematika Yang Berorientasi Pada High Order Thinking Skills. AKSIOMA: Jurnal Program Studi Pendidikan Matematika Volume, 9(3), 631-640.

Amilia, T. N., Andriani, N., \& Zulherman. (2016). Matematika Pokok Bahasan Bilangan Kompleks Di. Jurnal Inovasi Dan Pembelajaran Fisika, 3(2), 1-7.

Asrial, A., Syahrial, S., Maison, M., Kurniawan, D. A., \& Piyana, S. O. (2020). Ethnoconstructivism E-Module To Improve Perception, Interest, and Motivation of Students in Class V Elementary School. JPI (Jurnal Pendidikan Indonesia), 9(1), 30. https://doi.org/10.23887/jpi-undiksha.v9i1.19222

Asrowi, Hadaya, A., \& Hanif, M. (2019). The Impact of Discovery Learning on Students' Mathematics Learning Outcomes. International Journal of Instruction, 1320(1), 709-722. https://doi.org/10.1088/17426596/1320/1/012038

Astalini, Darmaji, Kurniawan, D. A., \& Simamora, N. N. (2021a). Comparison of Perception and 
Implementation of Mathematical Physics for Matrices. Jurnal Pendidikan Fisika Dan Keilmuan (JPFK), 7(1), 53-72.

Astalini, A., Darmaji, D., Kurniawan, D. A., \& Simamora, N. N. (2021b). Mathematical physics e-module: A study of students ' perception based on gender. Momentum: Physics Education Journal, 5(2), 209-226.

Busetto, L., Wick, W., \& Gumbinger, C. (2020). How to use and assess qualitative research methods. Neurological Research and Practice, 2(1). https://doi.org/10.1186/s42466-020-00059-z

Darmaji, D., Kurniawan, D. A., Astalini, A., Kurniawan, W., Anwar, K., \& Lumbantoruan, A. (2019). Students' perceptions of electronic's module in physics practicum. Journal of Education and Learning (EduLearn), 13(2), 288-294. https://doi.org/10.11591/edulearn.v13i2.13005

Ellianawati, \& Wahyuni, S. (2012). Pengembangan Bahan Ajar Fisika Matematika Berbasis Self Regulated Learning Sebagai Upaya Peningkatan Kemampuan Belajar Mandiri. Jurnal Pendidikan Fisika Indonesia, 8, 33-40. https://doi.org/10.15294/jpfi.v8i1.1992

Elmendorf, D. C., \& Song, L. (2015). Developing Indicators for a Classroom Observation Tool on Pedagogy and Technology Integration: A Delphi Study. Computers in the Schools, 32(1), 1-19. https://doi.org/10.1080/07380569.2014.967620

Goh, C. C. M., \& Hu, G. (2013). Exploring the relationship between metacognitive awareness and listening performance with questionnaire data. Language Awareness, 1-20. https://doi.org/10.1080/09658416.2013.769558

Ilmi, R., Arwana, I, M., Yerizon, \& Bakar, N, N. (2021). Development of an Android-Based for Math EModule by using Adobe Flash Professional CS6 for Grade X Students of Senior High School Development of an Android-Based for Math E-Module by using Adobe Flash Professional CS6 for Grade $\mathrm{X}$ Students of Senior High. Journal of Physics: Conference Series, 1742(1), 1-7. https://doi.org/10.1088/1742-6596/1742/1/012026

Kimianti, F., \& Prasetyo, Z. K. (2019). Pengembangan E-Modul IPA Berbasis Problem Based Learning Untuk Meningkatkan Literasi Sains Siswa. Jurnal Teknologi Pendidikan, 7(2), 91-103. https://doi.org/10.31800/jtp.kw.v7n2.p91-103

Lupi, J. B., Carvalho de Abreu, D. C., Ferreira, M. C., Oliveira, R. D. R. de, \& Chaves, T. C. (2017). Brazilian Portuguese version of the Revised Fibromyalgia Impact Questionnaire (FIQR-Br): cross-cultural validation, reliability, and construct and structural validation. Disability and Rehabilitation, 39(16), 16501663. https://doi.org/10.1080/09638288.2016.1207106

Odhier, P. O., Ajowi, J. O., \& Mwebi, B. (2019). Investigation on Contributions of Principals on School Machinery and Equipment Management in Secondary Schools in Kenya. International Journal of Novel Research in Humanity and Social Sciences, 6(5), 73-88.

Purnami, A. S., \& Winoto, B. (2020). Android-based shopping skill for mentally-disable student. Journal of Education and Learning (EduLearn), 14(3), 411-415. https://doi.org/10.11591/edulearn.v14i3.16110

Saputri, D. F., Fadilah, S., \& Wahyudi. (2016). Efektivitas Penggunaan Buku Ajar Fisika Matematika Berbasis Inkuiri dalam Perkuliahan Fisika Matematika. Jurnal Penelitian $\mathcal{E}$ Pengembangan Pendidikan Fisika, 2(2), 7 14. https://doi.org/10.21009/1.02202

Simamora, N. N., Putri, W. A., Iqbal, M., Ramadhanti, A., \& Rini, E. F. S. (2020). Description of Student Discipline Attitudes at SMP Negeri 16 Jambi City. Lensa: Jurnal Kependidikan Fisika, 8(2), 76-84.

Simpson, G. K., \& Lord, B. (2015). Enhancing the Reporting of Quantitative Research Methods in Australian Social Work. Australian Social Work, 68(3), 375-383. https://doi.org/10.1080/0312407X.2015.1035662

Sopacua, J., Fadli, M. R., \& Rochmat, S. (2020). The history learning module integrated character values. Journal of Education and Learning (EduLearn), 14(3), 463-472. https://doi.org/10.11591/edulearn.v14i3.16139

Sugiyono. (2020). Metode Penelitian Kualitatif. Bandung: Alfabeta.

Sumual, M. Z. I., \& Ali, M. (2017). Evaluation of primary School Teachers' Pedagogical Competence in Implementing Curriculum. Journal of Education and Learning, 11(3), 343-350.

Suparmi, Suardiman, S. P., \& Budiningsih, C. A. (2020). The pupil's creativity is inspired by experience through electronic media: Empirical study in Yogyakarta. International Journal of Instruction, 13(2), 637 648. https://doi.org/10.29333/iji.2020.13243a 